\title{
أثر الأوضاع الاجتماعية في فهم السنة النبوية واستنباط الأحكام الثرعية
}

\section{Fajar Rachmadhani}

Fakultas Agama Islam Universitas Muhammadiyah Yogyakarta

E-Mail: fajarrachmadhani@umy.ac.id

الملخص: يهدف هذا البحث إلى الكثف عن أهمية فهم السنة النبوية واستنباط الأحكام الشرعية منها

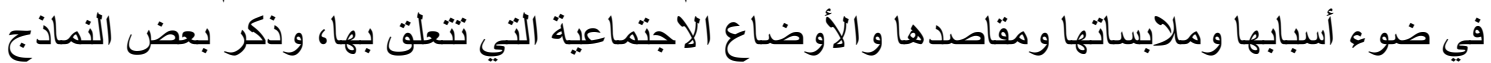

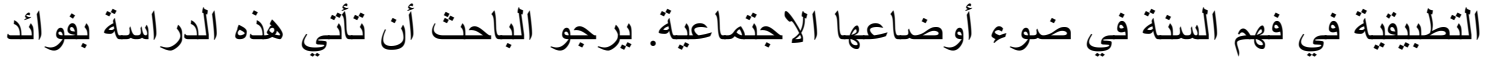

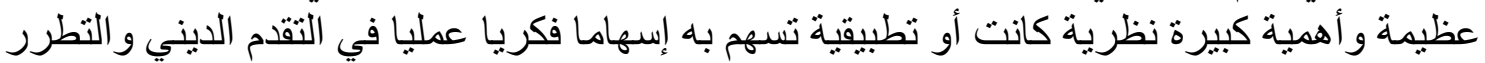

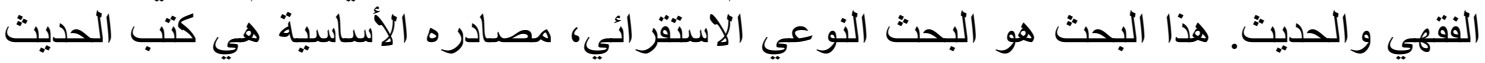

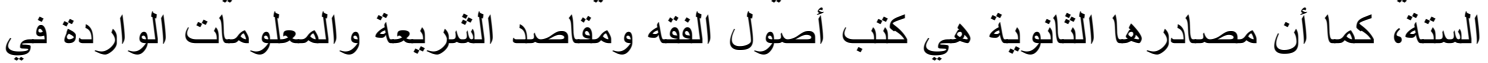

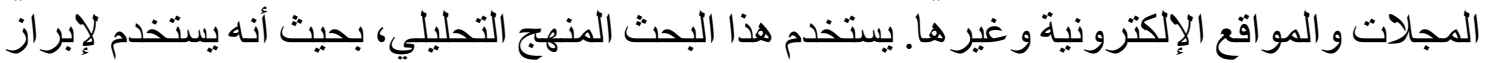

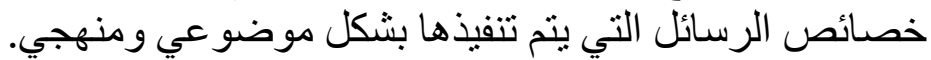

\section{الكلمات المفتاحية: الأوضاع الاجتماعية، فهم السنة، استتباط الأحكام الشرعية}

Abstract: The purpose this study is to discuss and uncover the urgency of understanding the hadith based on sociological conditions and the conclusion of Islamic law from it and show some examples related to it. The researcher hopes that this study will bring great benefits and great importance whether theoretical or applied contribute to it in a practical intellectual contribution to religious progress and the modern jurisprudence. This research is a qualitative inductive research, its main sources are the six Hadith books, and secondary sources are books of the principles of jurisprudence and the purposes of Sharia and information contained in magazines and websites and others. This research uses the analytical approach, so that it is used to highlight the characteristics of messages that are implemented objectively and systematically.

Keywords: sociological conditions, understanding hadith, juristic inference

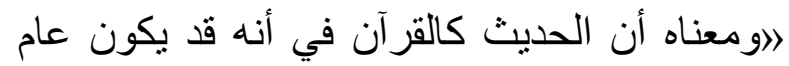

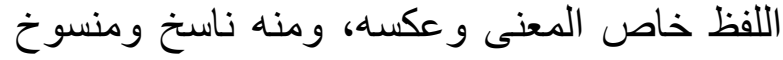

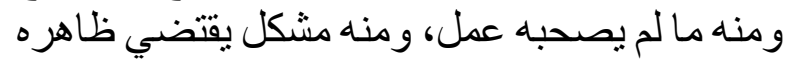

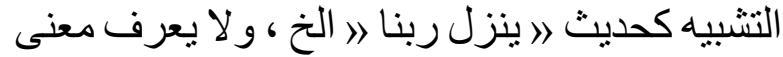
هذه إلا الققهاء《)

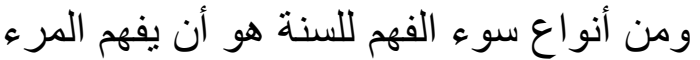
السنة فهما ظاهرا من غير أو أوها الالتفات إلى سياقها

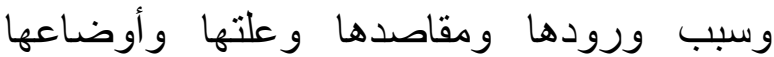

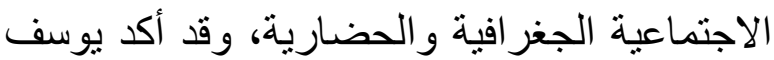

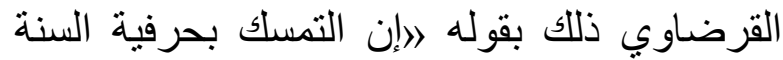

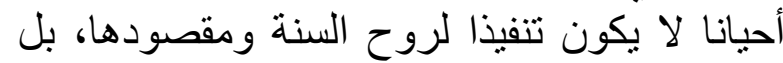

أحمد بن محمد بن علي بن حجر الهيتمي السعدي الأنصاري شهاب الدين شيخ الإسلام أبو العباس الفتاوى الحديثية، (القاهرة : دار الفكر، 2010

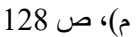

إن السنة هي المصدر الثاني للإسلام، في

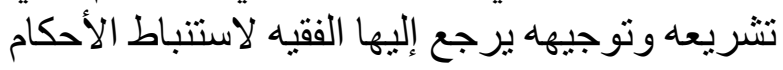

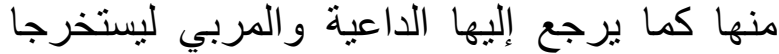

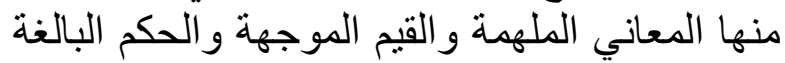
و الأساليب المر غبة في الخير و المر هبة عن الثر الثر فلا

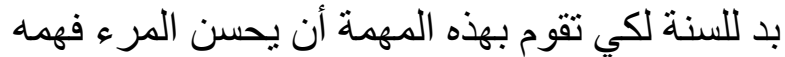

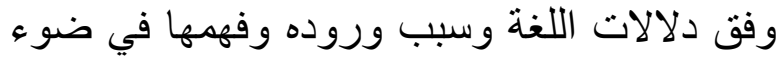

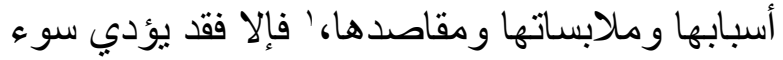

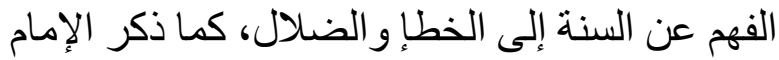

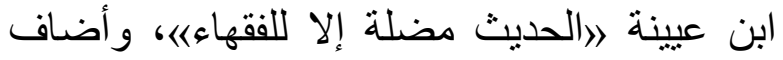
الإمام ابن حجر الهيتمي شارحا لللك القول بقوله لله

يوسف القرضاوي، كيف نتعامل مع السنة النبوية : معالم وضوابط، (القاهرة : دار الثروق، 2002 م)، ص 35 
و أفعال وتقريرات وأحكام إنما تبنى على الدعائم

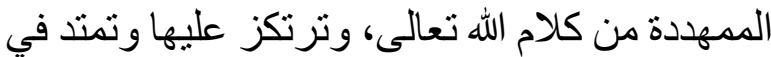

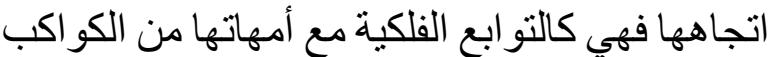

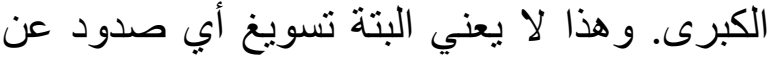

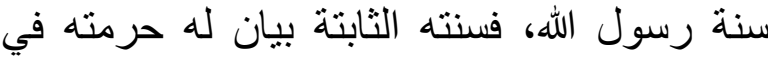

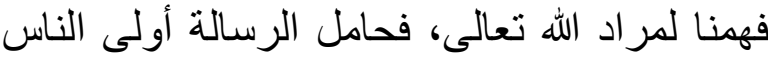

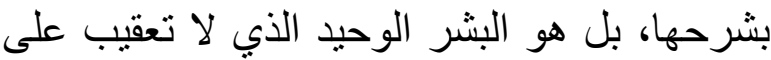
كلامه في هذا الميدان. إن أول معالم السنة النئ النبوية

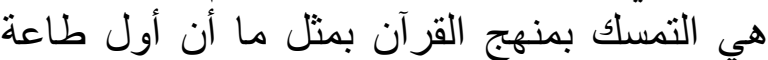
للقرآن هي المشي خلف رسول الله صلى الله الهي عليه

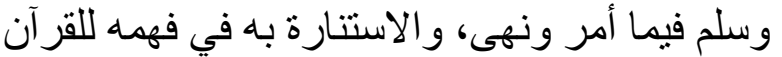

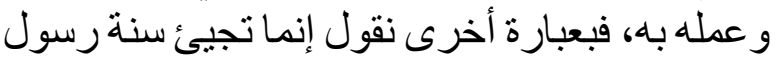
الله في عمومها وجملتها مو افقة للقر آن الكريم، تفصل

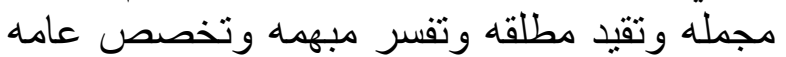
وتثرح أحكامه وأهدافه كما أنها قد تأتي بأحكام لم

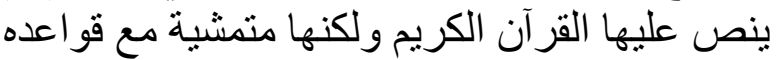
ومحققة لأهدافه وغاياته. أجمع العلماء على أن السنة لها مكانة عظيمة في الإسلام، وهي المصدر الثاني بعد القرأن الذي الذي لطي

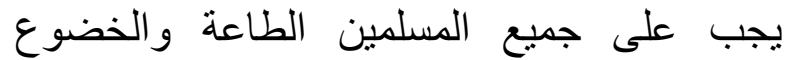

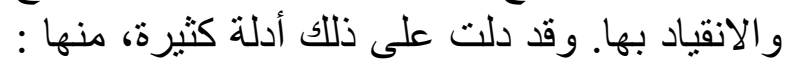

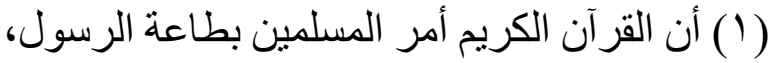

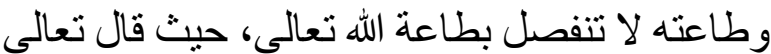

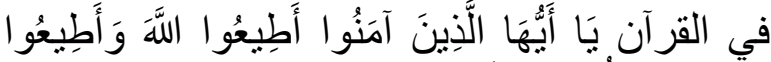

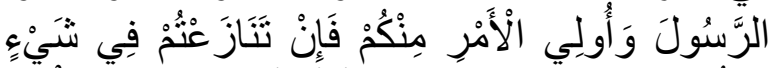

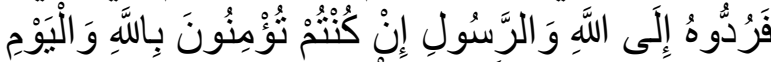

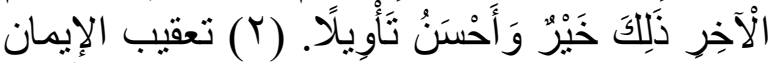

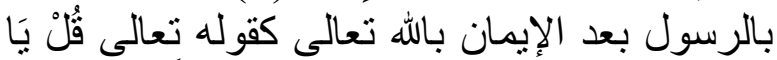

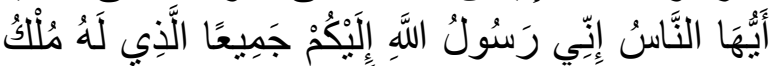

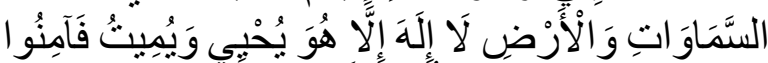

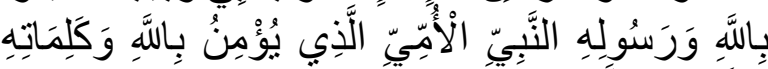

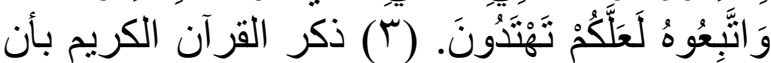

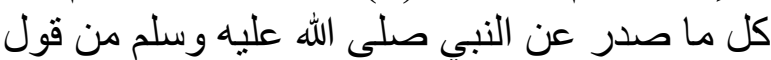

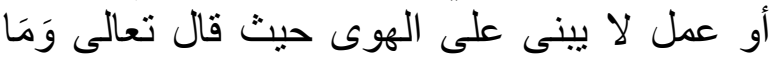

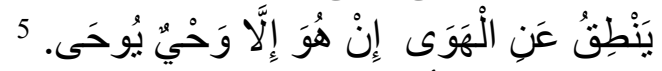

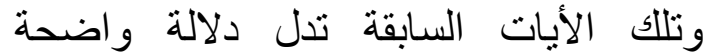
وصريحة في وجوب الأخذ بالسنة النبوية في الأدلة

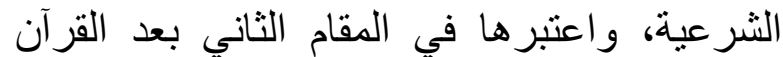
الكريم، ثم إن السنة النبوية جاءت شارية النارحة ومبينة

$5 \quad$ Fajar Rachmadhani, Kuliah Dasar Ulumul Hadis : Kajian Terminologis Dan Metodologis (Yogyakarta: Samudra Biru, 2019).
يكون مضادا لها، و إن كان ظاهره التمسك بهاهـ"

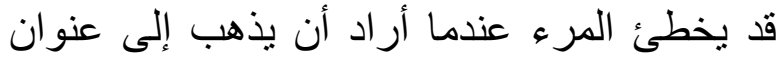

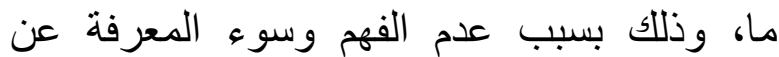
العنوان الدقصود، ولو كان العنوان صحيحا، قياسا

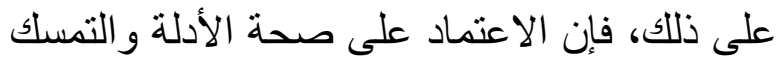
بثبوتها لا يكفي لاستنباط الأحكام منها، بل نحتاج الإن إلى اللى

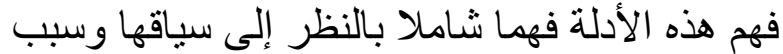

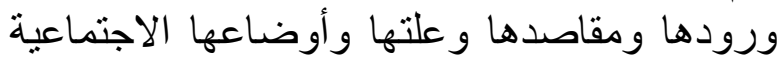

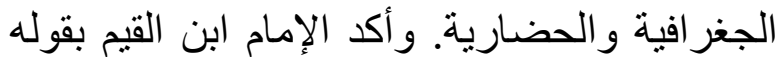

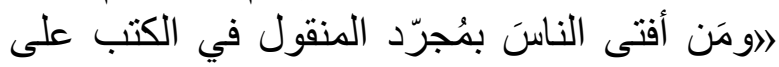

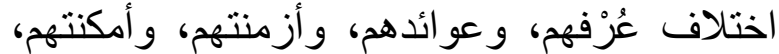

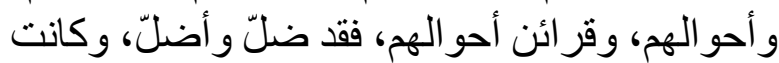

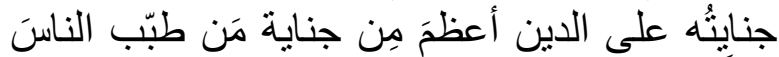

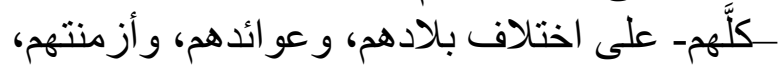

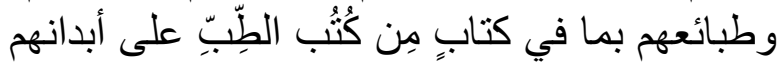

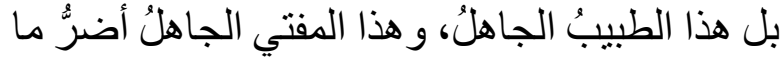
على أديانِ الناسِ و أبدانِهم و الله المستعانها. منهجية البحث

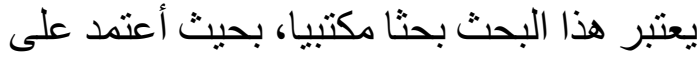
المصادر أو المراجع أو الكتب المكتبية. ومن ثمثيث اعثى فإن أداة جمع البيانات والمعلومات الئمات المستخدمة في هذا البحث هي قراءة كتب الأحاديث وأصول أصول الفقه ومقاصد الثريعة والمجلات و النشرات واتئ والمقالات العلمية المرتبطة بهذا الموضوع. فئلون نظرا إلى طبيعة الموضوع، فقد استخدمت في هذا البحث المثن المنهج

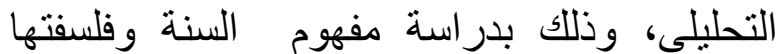
و أهمية فهم السنة في ضوء أسبابها وملابساتها ومقاصدها، وبعض النماذج التطبيقية في فهم السنة

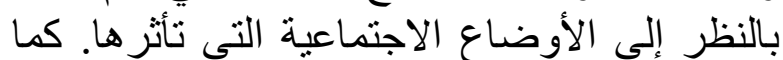

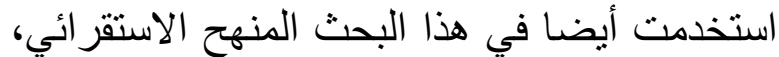

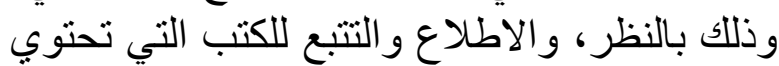
على معلومات حول الأحاديث وأصول لكول الفقهو ومقاصدي

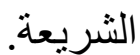

\section{العرض} فلسفة السنة ومكاتتها في الإسلام إن سنن السول صلى الله عليه وسلم من أقوال

\footnotetext{
يوسف القرضاوي، كيف نتعامل مع السنة النبوية : معالم وضو ابط، ص 3 138

ابن القيم الجوزية، إعلام الموقعين عن رب العالمين، (بيروت : دار 4 الجيل، 1973 م)، ص 470
} 
الطعام و الثر اب عند الجوع أو الظمأ وكذهابه

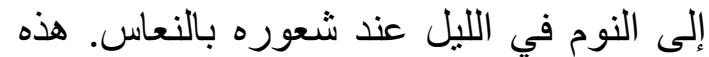

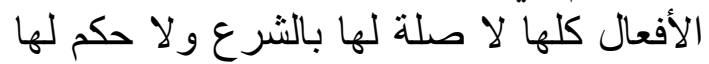

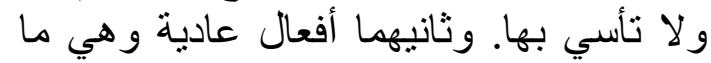
فعله الرسول صلى الله عليه وسلم في الإطار الذي سمح به الفضاء الثقافي والإجتماعي الإسي

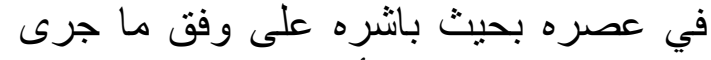

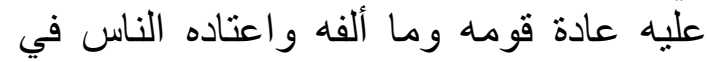

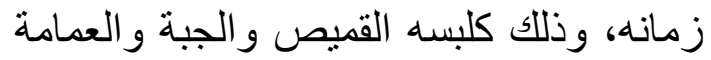

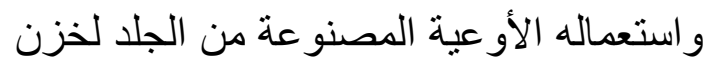

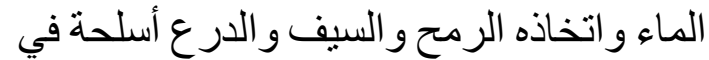
الحرب وكركوبه الجمل في السير أو السفر إلى النى الني

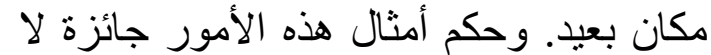

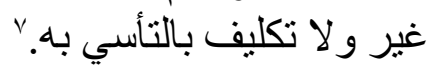

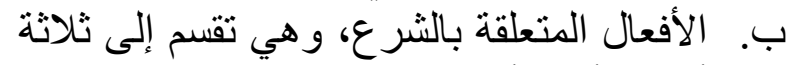
أنواع، أولها أفعال خاصة بالنالنبي صلى اللى الله عليه

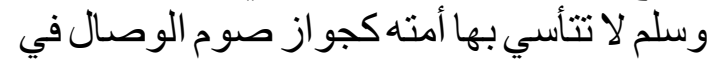

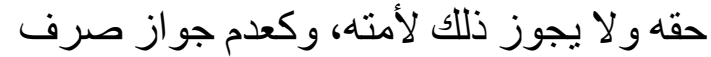
الزكاة والصدقة إليه مع جواز ذلانه للك للأفراد المستحقين لها من أمتها، وكوجوب الكع التهو التهد عليه بينما هو مسنون بالنسبة لأمتاه. وثانيها أفعال

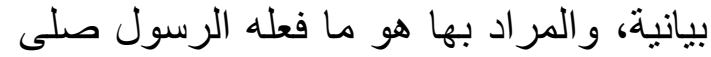

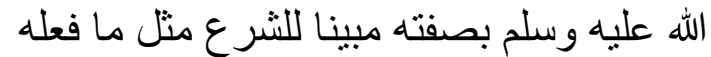
في العبادة مثلا، فقد فال بشأن الصلاة (صلوا

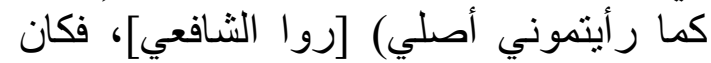

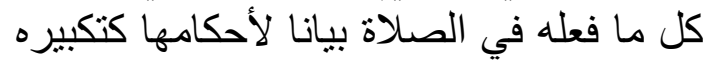

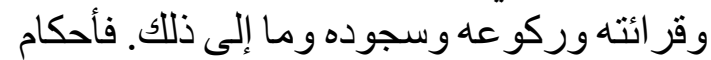

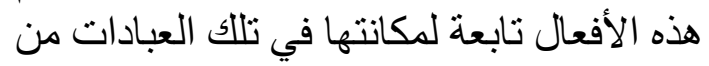

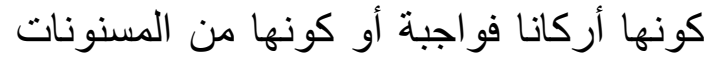

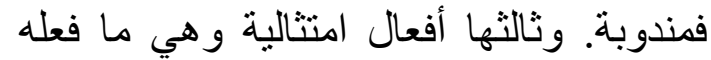

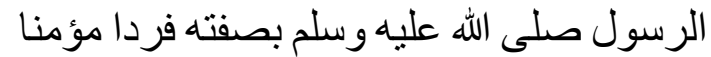
يؤدي تعاليم دينه. في الحقيقة الأفعال الامتثالية

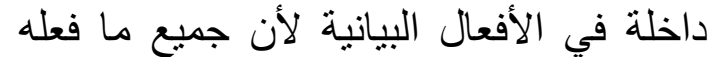

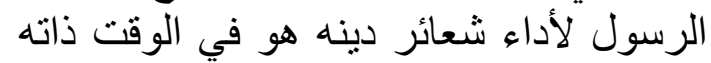

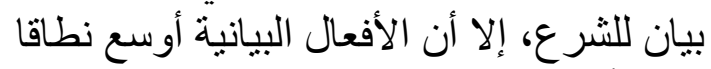

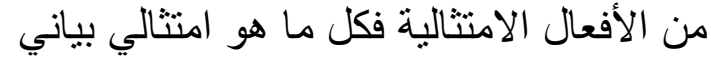

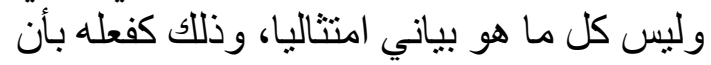

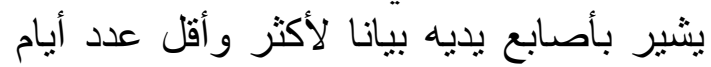
الثهر القمري وليس هذا على لئ الأصح امتنثالا.

\footnotetext{
شمس الأنوار، أصول الفقه : دراسة نقدية في آلبات اكتشاف الأحكام

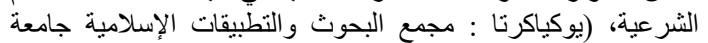

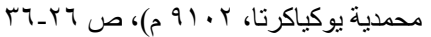

ومفسرة لكثيرة مما جاء في القر آن الكريم من أحكام مجملة لا يمكن معرفتها إلا من حديث التران الكريت رسول الله

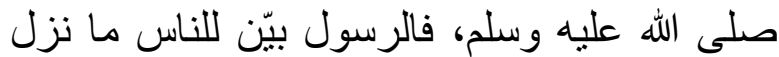

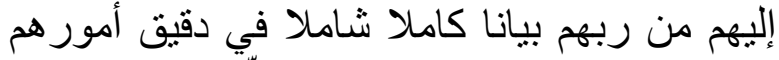

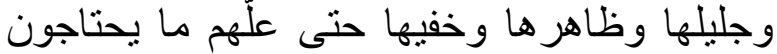

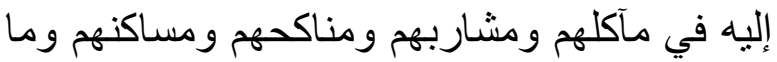
يحتاجون إليه في عبادة الله، وما يحتاجون إليه في

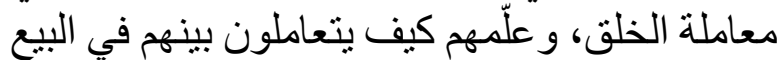

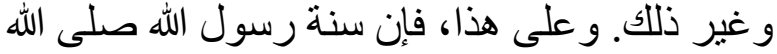

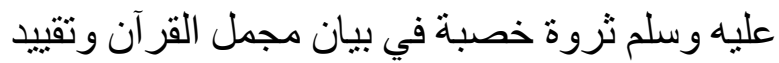
مطلقه وتخصيص عامه ونتشريع أحكامه التي لم يأت

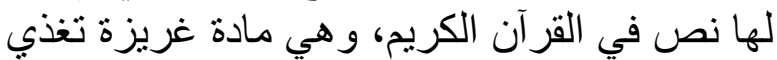

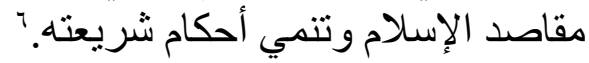

أفعال النبي صلى الله عليه وسلم كان النبي صلى الله عليه وسلم قدئ قدوة صالحة

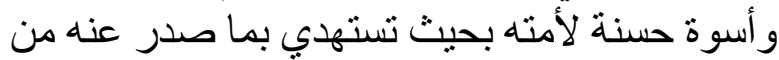
أقو ال و أفعال وتقرير الاته، وبين القر آن هذه الحقيقة في في قوله تعالى 》القد كان لكم في رسول الله أسوة حسنة لمن كان يرجو الله واليوم الآخر وذكر الله كثير الها.

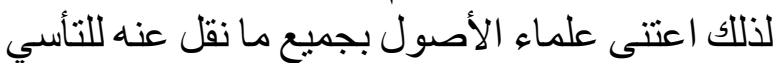

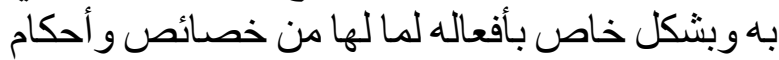
خاصة. كانة الأفعال الصادرة عنه صله صلى الله عليه

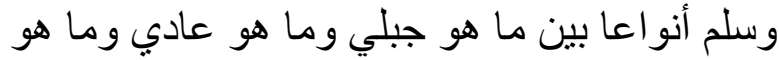

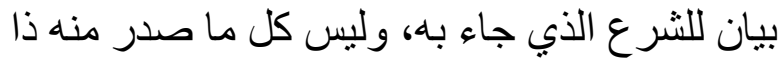
أهمية تشريعية. ولذلك قسم علماء ألى أصول الفقه أفعاله

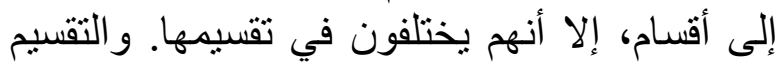
البسيط غير المعقد حسب رأي الكاتب أنها أنها من حيث

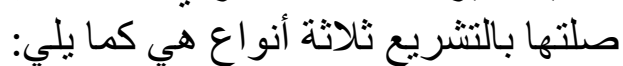

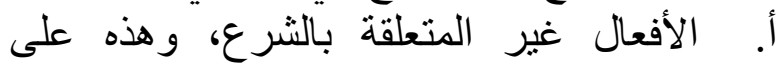

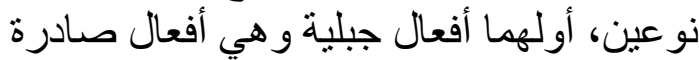

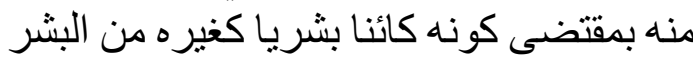

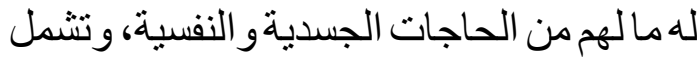
هذه الأفعال ما فعله النبي صلى الله عليه وسلم الله

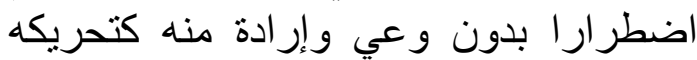

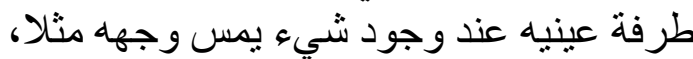
كما تشمل ما فعله عن قصد و اختيار منه بحيث ونيث

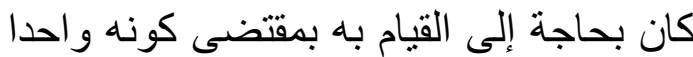
من المخلوق البشري لا مفر لله منه كتناوله

سليمان بن عبد الله أبا الخيل، مصادر الدين الإسلامي وأبرز محاسنه

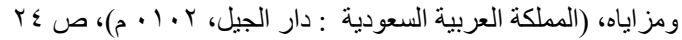


فيها النص، و انتقت العلة الملحوظة من ور اءه من مصلحة تجلب أو مفسدة تدفع فالمفهوم أن بنتفي الحكم

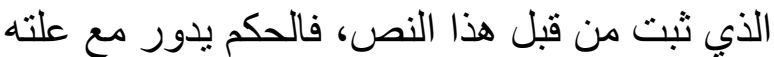

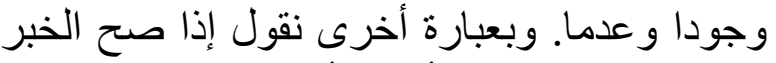

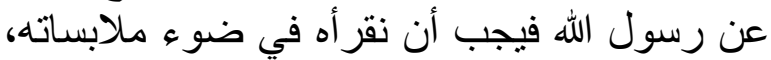

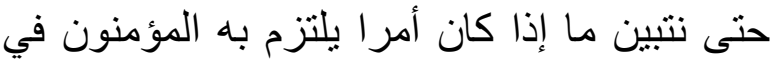

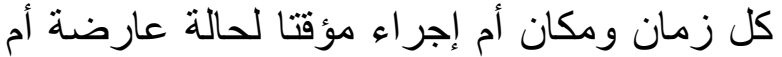

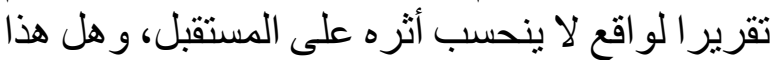
القول من النبي صلى الله عليه وسلم قصد به التشريع التهايع

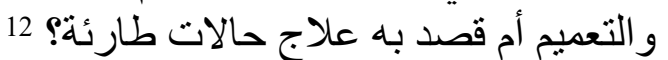

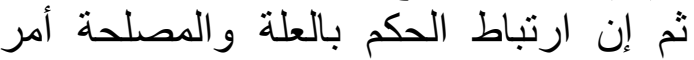
آخر له أهمية كبرى في استقبال الأحاديث النبوية استقبالا صحيحا، فقد تكون العلة طارئة كما قد تكون الهن

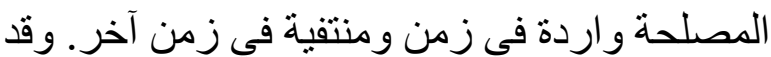

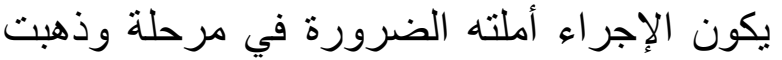

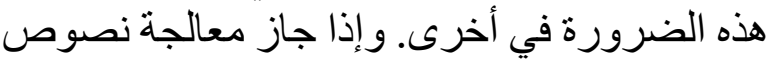

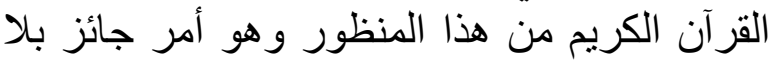
شك، و المثال على ذللك اجتهاد عمر في سهم المؤلفة

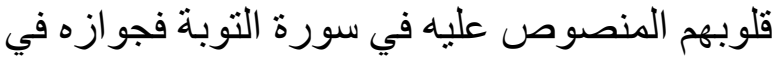
نصوص السنة الصحيحة أدعى. فقد يصدر الأمر

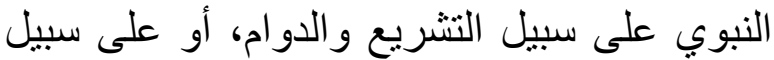

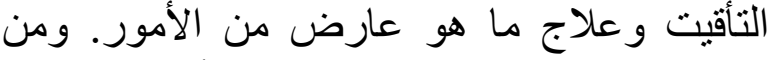

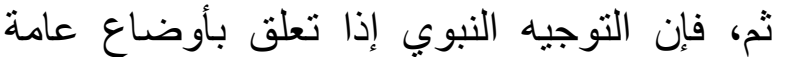

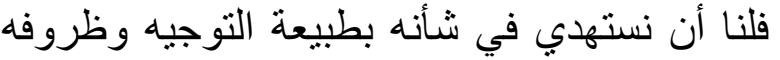
التاريخية، ثم بتعبيره عن المنطلقات الأساسية في فئهي

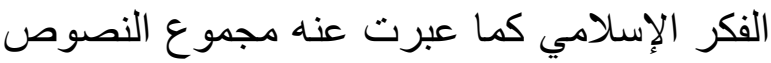

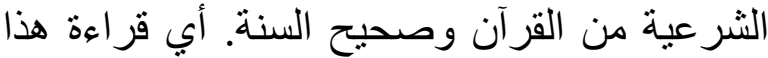

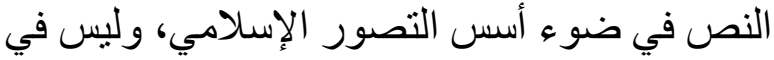
ضوء نصوص مؤقتة ارتأتها السياسة أو المصلحة الأحة وله

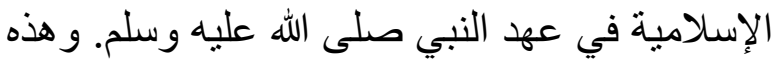

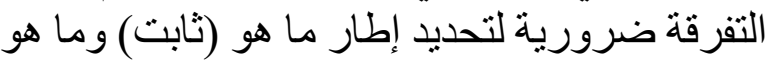

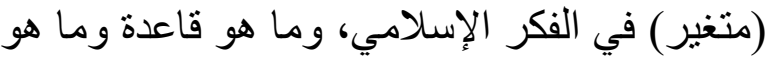
استثناء.

\section{النماذج الآثارية للأوضاع الاجتماعية في السنة النبوية ا ـ. الانتعال عند الصلاة}

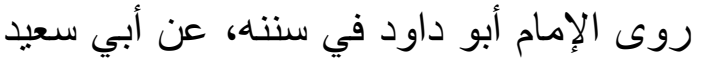

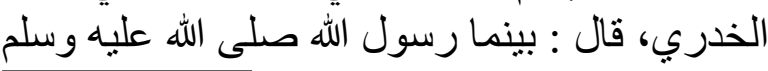

رضا جاد، في فقه الاجتهاد والتجديد دراسة تأصيلية تطبيقية، (القاهرة : دار السلام 12

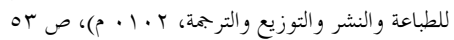

8 الأفعال المشكوك في صلتها بالثرع، أي المترددة بين كونها غير متعلقة بالثرع وبين كونها متعلقة به. وذللك مثل جلوس الاستر احة

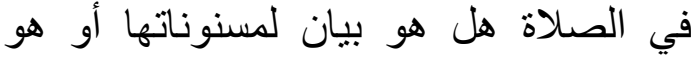

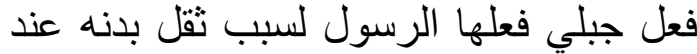
شيخوخته وليس من أفعال الصلاة.

\section{أهمية فهم السنة في ضوء أسبابها وملابساتها \\ ومقاصدها}

من الأمور المهمة في فهم السنة النبوية و استنباط الأحكام الثرعية منها وهو فهر السنة في ضوء أسبابها وملابساتها ومقاصدها. ومن فئن

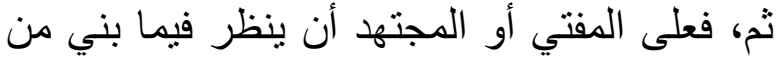

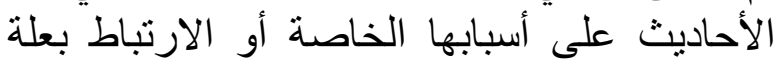
معينة منصوص عليها أو مستنبطة منه أو مفهومة الآنة من الو اقع الذي سيق إليها الأيات أو الأحاديث.

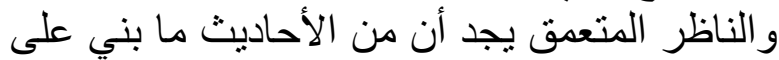
رعاية ظروف زمنية معينة أو أوضاع اجتماعية

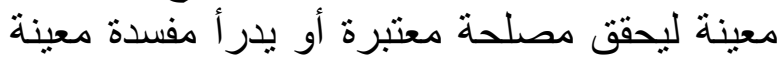

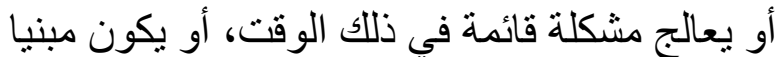

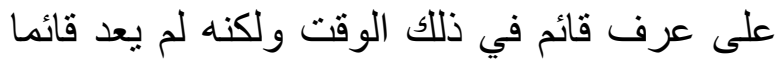
اليوم. و هذا يحتاج إلى فقه عميق ونظر دقيق ودئ ودر اسة

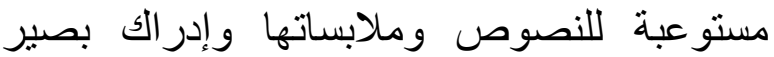

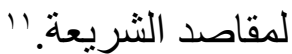
و إنه لا بد من معرفة السياق و الملابسات التي

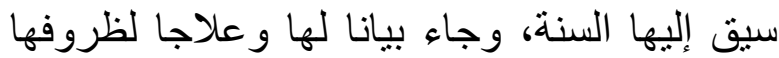
حتى يتحدد المر اد من الحديث بدقة، لأن السنة كثير النياء

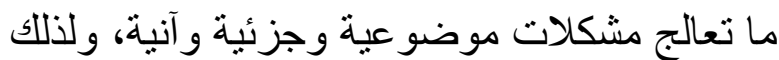

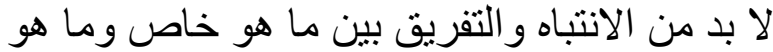

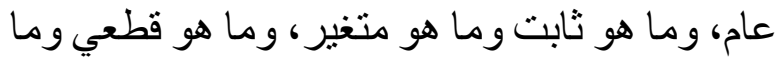

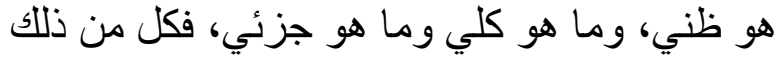

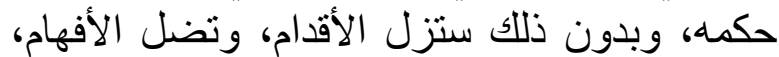

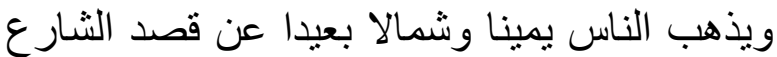

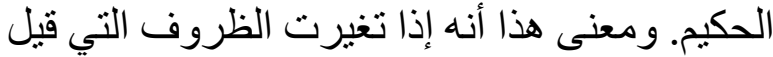

8 Muthoifin, Mengungkap Isi Pendidikan Islam Perspektif Al-Qur' an Surat Al-Ashr Ayat 1-3, Proseding the 7th University Research Colloqium 2018 STIKES PKU Muhammadiyah Surakarta, 2018.

9

10 Munawir Muin, 'Pemahaman Komprehensif Hadis Melalui Asbab Al-Wurud', Addin, 7.2 (2015).

11 Liliek Channa Aw, 'Memahami Makna Hadis Secara Tekstual Dan Kontekstual', Ulumuna, 15.2 (2011), 391-414. 
على الناس الغفلة عن العناية بنعالهم حين يدخلون المسجد.

يرى بعض علماء الحنابلة بأن الصلاة في

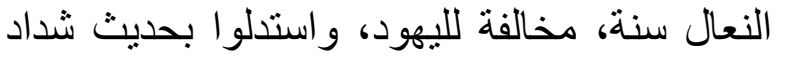

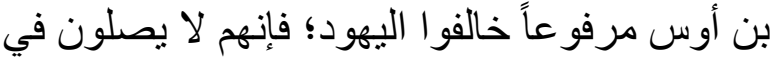

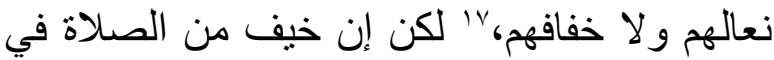

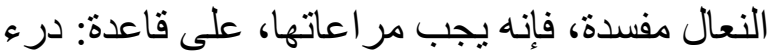

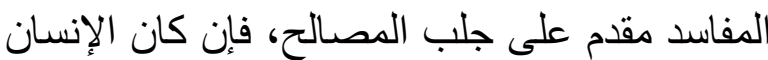
في أرض حصباء أو في البر جاز أن أن بصلي في الإنيان

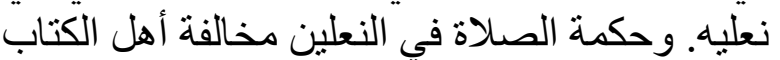

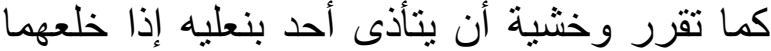

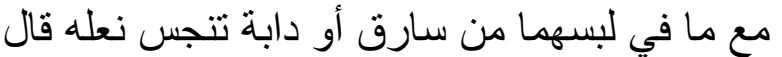

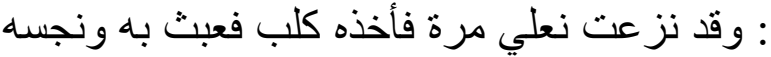

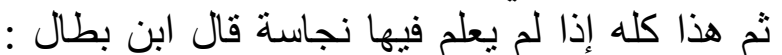

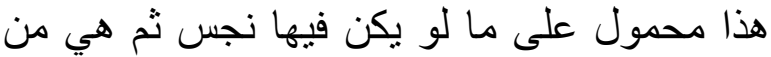

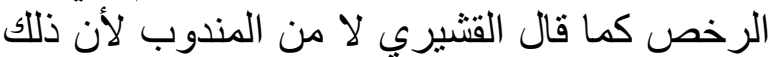

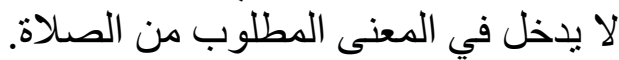

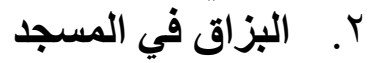

روى الإمام البخاري عن أنس بن ماللك رضي

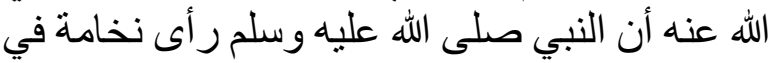
القبلة فثنق ذللك عليه رؤي في وجها النها فقام فحكه بيدها.

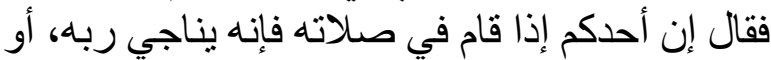
إن ربه بينه وبين القبلة. فلا ييزقن أحدكم قبل قبلته فئه. ولكن عن يساره أو تحت قدميه. ثم أخذ طرف رئه ردائه

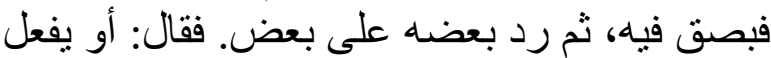
هكذا.

كما روى أيضا عنها، أن النبي صلى الله عليه وسلم قال: إن المؤمن إذا كان في الصناة فئان إنما يناجي

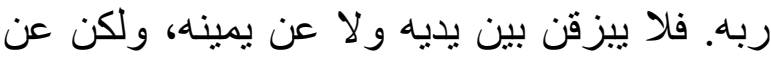

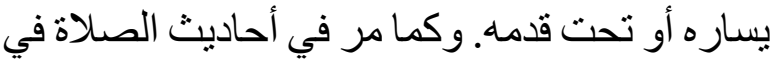

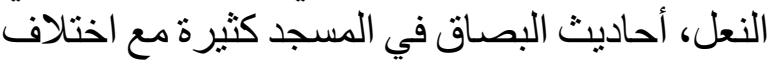

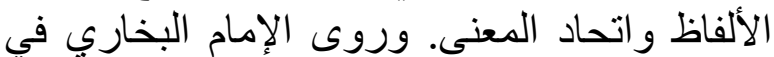

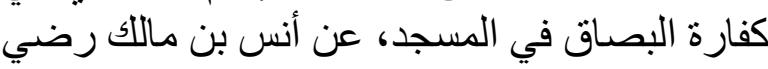

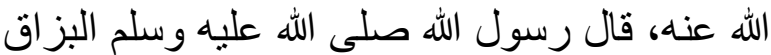
في المسجد خطيئة وكفارتها دفنها.

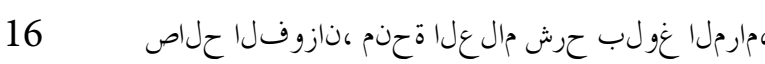

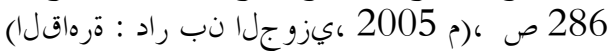

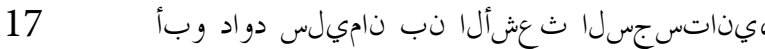

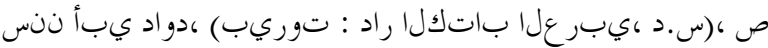

يراخبل الحيحص ،يراخبل ال لي عامسإ نب دمحت

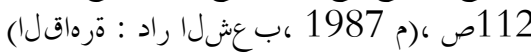

يصلي بأصحابه إذ خلع نعليه فوضعهما عن يساره،

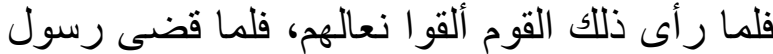

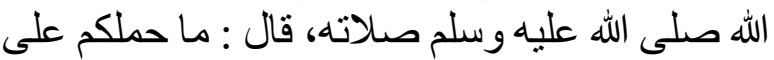
إلقاء نعالكم، قالو ا : ر أيناك ألقيت نعليك فألفيه ألقينا نعالنا،

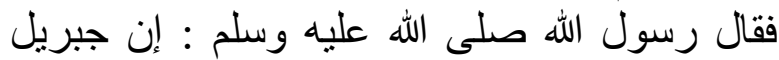

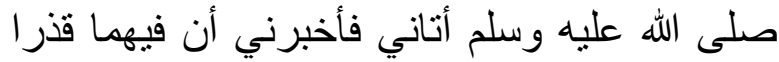

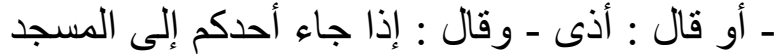

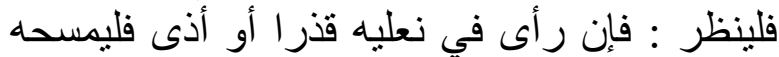

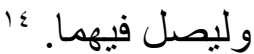

دل الحديث السابق على استعمال النبي صلى الله

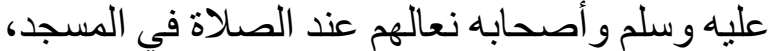
فهل نقول بأن من السنة أن نصلي في مساجدنا اليوم

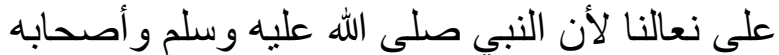

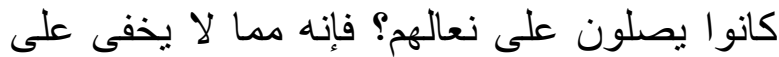

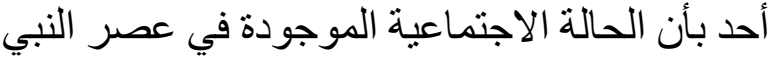

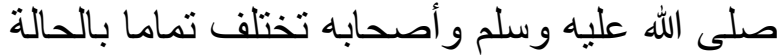

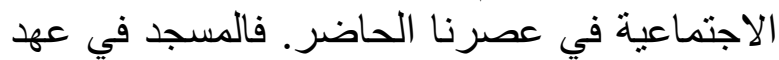

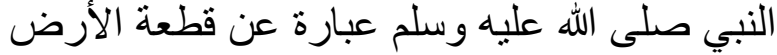
المربعة تحيطها السور والحيه ولئط بحيث أن أرضه

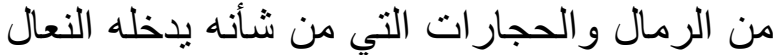

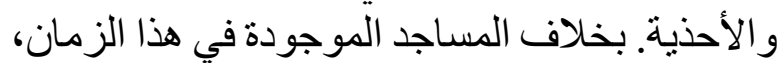
فإن أرضها تتكون من السر اميك أو الرخام بل هي

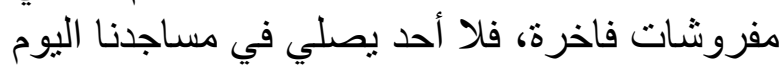
على نعالهم وأحذيتهم عملا بظاهر الحديث السابق.

ذكر الثنيخ عبد الله بن صالح الفوزان في كتابه منحة العلام شرحا للحديث السابق بأن المساجد قديماً تفرش بالحصباء والرمل ونحو ذللك، فيصلى فئل فيها

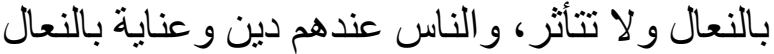

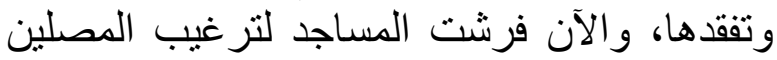

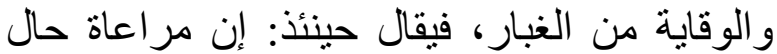

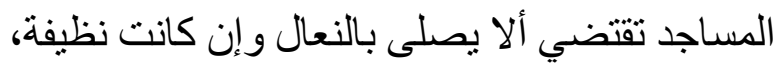
لأمرين، الأول: أن المساجد لا تسلم من تلويث فالن فرشها

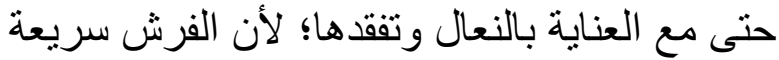

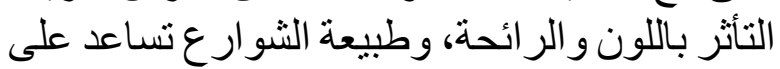

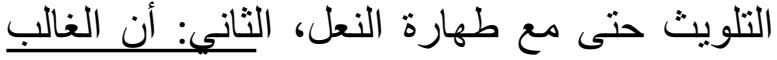

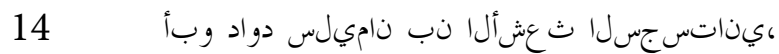

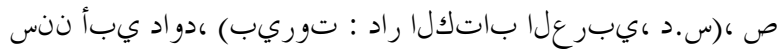
247

ة 15

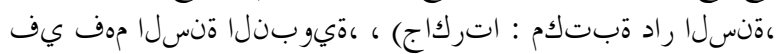
113 
ثم بعد ذلك، هل نقول أن التبرز خارج المنزل

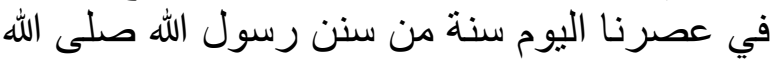

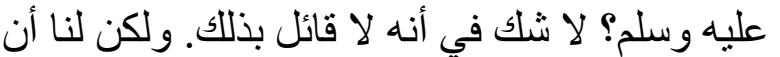

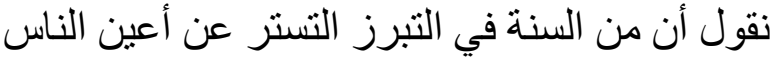

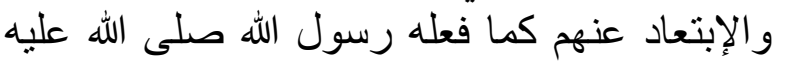
وسلم. وقد حصل هذا عند الناس اليوم في تبرز هـ الند بعيدين عن أعين الناس وتستر هم عنهم، وإن كان كان ذللك داخل مناز لهم. هذه هي سنة النبي صلي التى الله عليه

ومن ناحية أخرى، اتهم بعض أعداء الإسلام

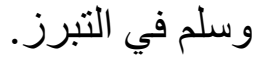

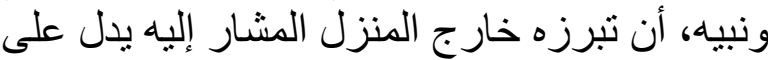

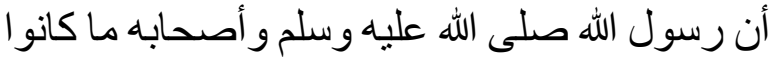

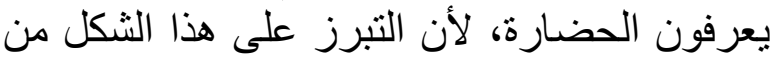

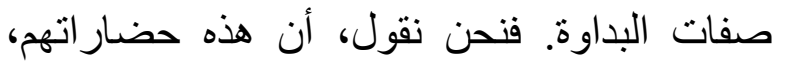

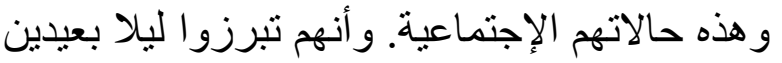

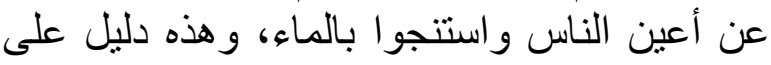

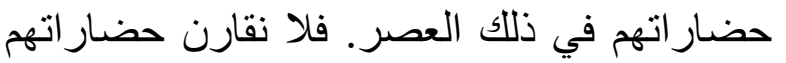

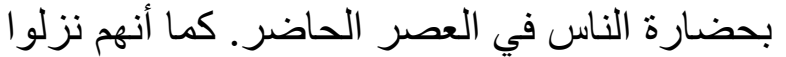

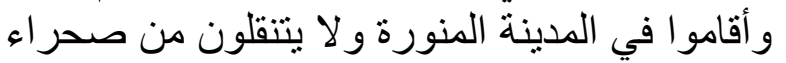
إلى صحر اء. فهذا دليل على حضار اتهم في ذلك التئل

\section{خاتمة البحث}

بناء على ما ذكر في هذا البحث، يتبين لنا

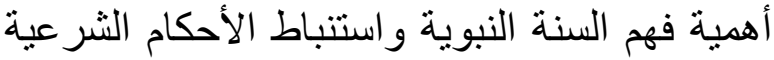

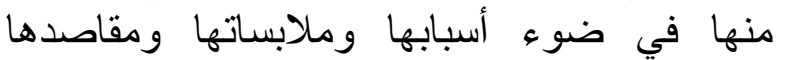

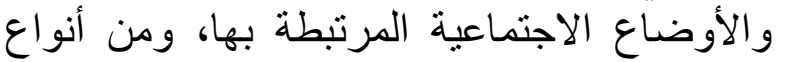

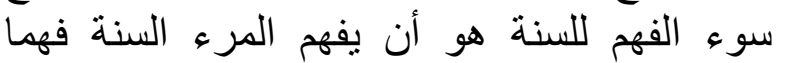

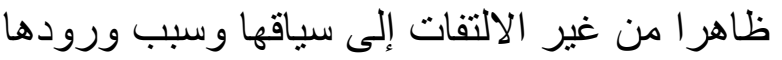

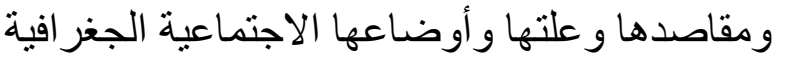

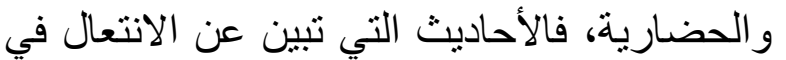

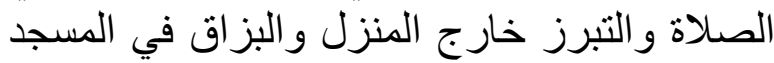

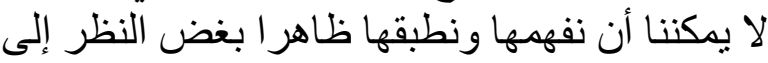

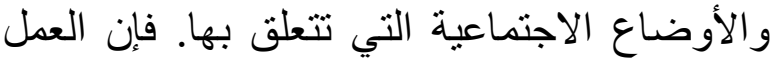

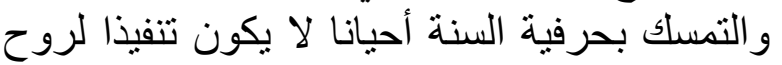

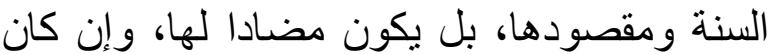
ظاهره التمسك بها.

136 ص ، 2016
لا شك أن أرض المسجد في العهد النبوي

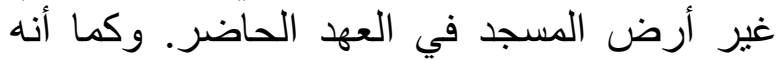
جاز الصلاة في النعل في المسجد، جاز البزان العاق في المسجد إلا أن هذا يعتبر خطيئة وكفارتها دفنها. وهذه الأحاديث لا يجوز العمل بها لفظا في المساجد

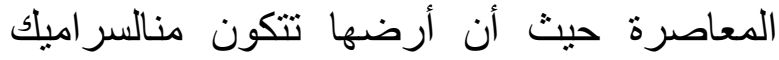

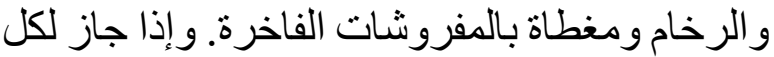

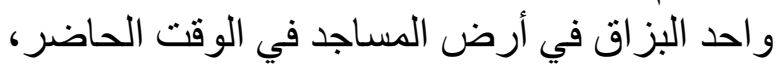

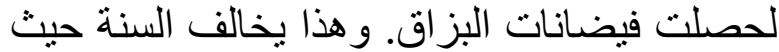

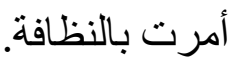

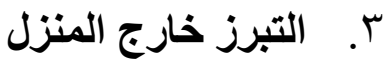
وروى الإمام البخاري في صحيحه عن أنس بن ماللك رضي الله عنه، قال: كان رسول الإن الله صلى الهي الله

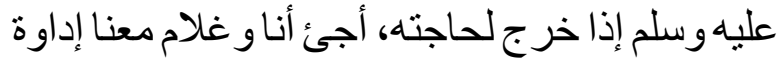

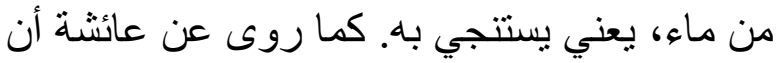

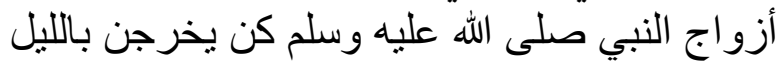
إذا تبرزن إلى المناصع، و هو صعيد أفيح. فكان عمر بلى بلى

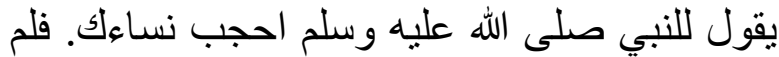
يكن رسول الله صلى الله عليه وسلم يفعل. فخرجت الله

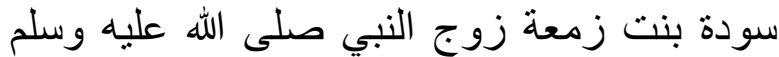
ليلة من الليالي عشاء، وكاني وكانت امر أة طويلة. فناداها

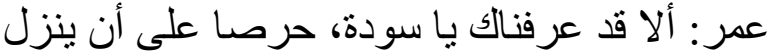
الحجاب. فأنزل الله آية الحجاب. دلت هذه الأحاديث على أن رسول الله صلى الهى

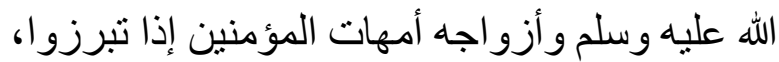

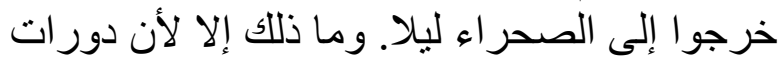

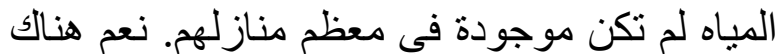
منزل لأم المؤمنين حفصة بنت عمد عمر ، له له دورة مياه

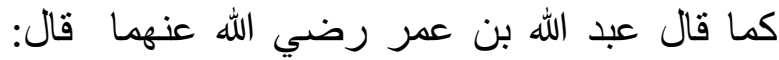

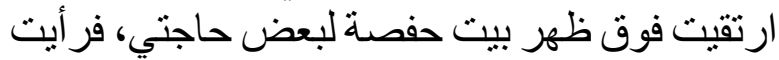
رسول الله صلى الله عليه وسلم يقضي حاجاته مستدبر القبلة مستقبل الثنام. و هذه هي حالاتهم الاجتماعية،

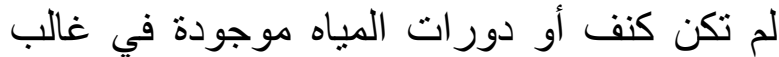

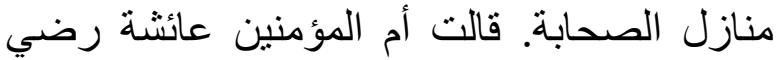

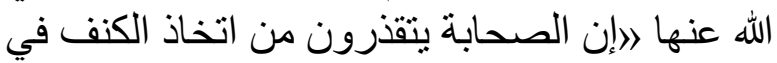

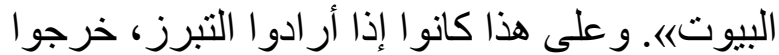

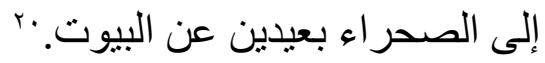

19

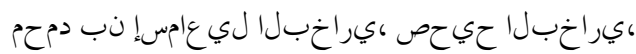

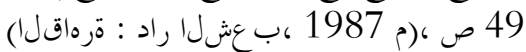

ة 20

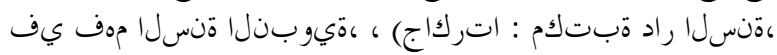


كيف نتعامل مع السنة النبوية : معالم وضو ابط، يوسف القرضاوي، الناشر : دار الثروق - القاهرة، ط : r...r

الفتاوى الحديثية، أحمد بن محمد بن علي بن حجر الهيتمي السعدي الأنصاري، شهاب الدين شيخ الإسلام،

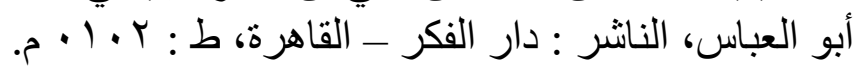

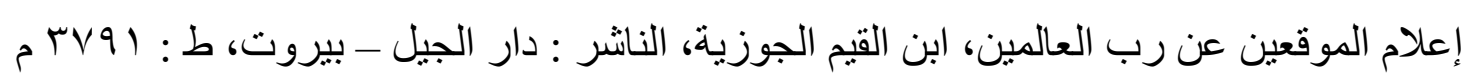

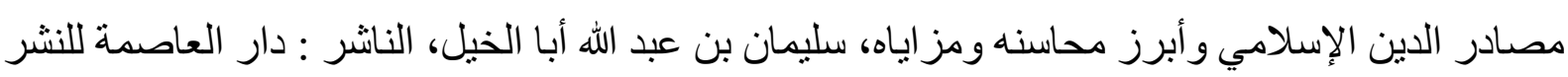

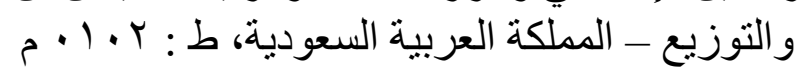

أصول الققه : دراسة نقدية في آليات اكتشاف الأحكام الثرعية، شمس الأنوار، الناشر : مجعع البحوث

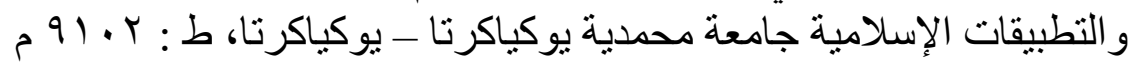

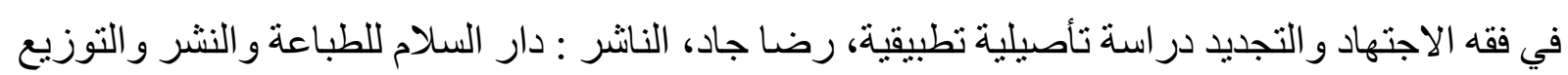

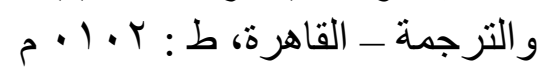

سنن أبي داود، الإمام أبو داود سليمان بن الأشعث السجستاني، الناشر : دار الكتاب العربي - بيروت.

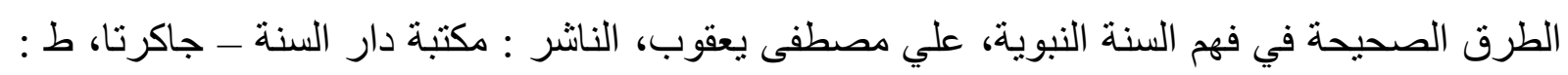
. $71 \cdot r$

منحة العلام شرح بلوغ المر ام، صالح الفوزان، الناشر : دار بن الجوزي ـ القاهرة، ط : ؟ . . م م.

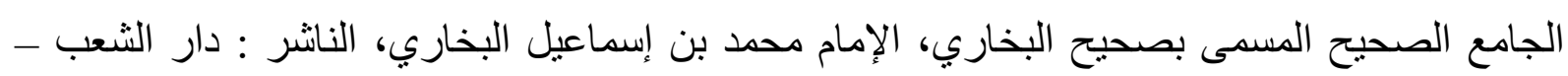

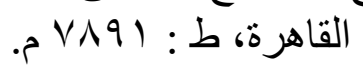

Fajar Rachmadhani, Kuliah Dasar Ulumul Hadis : Kajian Terminologis Dan Metodologis (Yogyakarta: Samudra Biru, 2019).

Munawir Muin, 'Pemahaman Komprehensif Hadis Melalui Asbab Al-Wurud', Addin, 7.2 (2015).

Muthoifin, Mengungkap Isi Pendidikan Islam Perspektif Al-Qur'an Surat Al-Ashr Ayat 1-3, Proseding the 7th University Research Colloqium 2018 STIKES PKU Muhammadiyah Surakarta, 2018.

Liliek Channa Aw, 'Memahami Makna Hadis Secara Tekstual Dan Kontekstual', Ulumuna, 15.2 (2011), 391-414. 